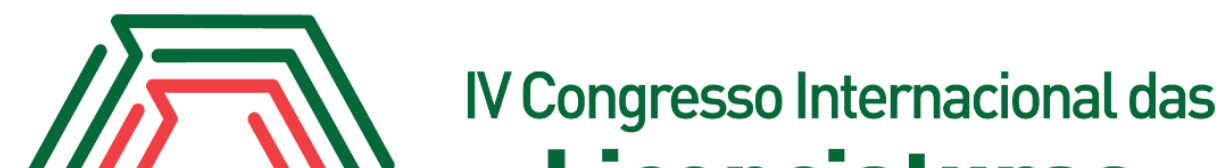 Licenciaturas COINTER - PDVL 2017
}

\section{A UTILIZAÇÃO DO JOGO "ISOQUANT" COMO FERRAMENTA NO ENSINO DE QUÍMICA}

\author{
Apresentação: Relato de Experiência
}

Ruth Ramony Tavares de Queiroz ${ }^{1}$; Naiane Ferreira Leite ${ }^{2}$; Caio Patrício de Souza Sena ${ }^{3}$; Francisca Sheldakelle Holanda Torres Pinheiro ${ }^{4}$

\section{Introdução}

O estudo da química requer, muitas vezes, o entendimento de conceitos abstratos que se trabalhados de maneira puramente tradicional pode gerar uma falta de motivação, tornando esses conhecimentos mais difíceis de serem construídos pelos alunos. Segundo Fialho[1], “A exploração do aspecto lúdico, pode se tornar uma técnica facilitadora na elaboração de conceitos, no reforço de conteúdo, na sociabilidade entre os alunos, na criatividade e no espírito de competição e cooperação...". E neste contexto surge o uso dos jogos didáticos, como uma ferramenta diferenciada para resgatar o interesse dos aprendizes e auxiliar no processo de ensino-aprendizagem, pois proporciona ao discente um meio divertido de aprender, que possibilite e estimule o desenvolvimento de habilidades cognitivas, promovendo a socialização e a cooperação. O presente trabalho relata uma experiência de produção e aplicação de um jogo didático como ferramenta facilitadora para o ensino de química, mais especificamente estrutura atômica e distribuição eletrônica. Foi desenvolvido como uma ação do Subprojeto Química Pau dos Ferros do PIBID-IFRN.

\section{Relato de Experiência}

Por acreditar na eficácia desta ferramenta, foi desenvolvido um jogo com o objetivo de facilitar aprendizagem dos conceitos de (isótopos, isóbaros e isótonos) e a distribuição eletrônica. Sendo este aplicado com estudantes do $1^{\circ}$ ano do Ensino Médio da Escola Estadual Tempo Integral Doutor José Fernandes de Melo em Pau dos Ferros/RN. Os jogos foram confeccionados com materiais de baixo custo e fácil acesso: cartolina, pincéis, cola e isopor. Robaina [2] destaca as facilidades de criação dos jogos, pois podem ser confeccionados com materiais que faz parte do ambiente de sala de aula. Destaca ainda a facilidade de aplicação, pois pode ser aplicado no ambiente que se queira. Dois grupos foram formados, e um integrante do grupo foi escolhido para jogar o dado.

\footnotetext{
Licenciatura em Química, IFRN/campus Pau dos Ferros, ruth_ramony@live.com Licenciatura em Química, IFRN/campus Pau dos Ferros, naianeferreira4@gmail.com Mestrado em Química, IFRN/campus Pau dos Ferros, caio.sena@ifrn.edu.br Doutorado em Química, E.E.Dr José Fernandes de Melo, sheldakelle@ yahoo.com.br
} 
O que obtive-se a maior pontuação começaria o jogo andando o número de casas que surgiu no dado. E então responderia a pergunta, de acordo com o número e cor da casa. A cor azul corresponde a uma questão fácil e vale 2 pontos e a cor vermelha é uma questão difícil valendo 4 pontos. A equipe que concluir a chegada com a maior pontuação venceria o jogo. Ficou evidente que os alunos conseguiram melhorar o entendimento sobre o conteúdo abordado, pois, numa aula seguinte a professora propôs questões do livro, onde os alunos teriam que responder as questões com a ajuda da mesma. Sendo assim os alunos mostraram domínio de conteúdo, dessa forma, fazendo com que o rendimento fosse o esperado. Além disso, houve a desmistificação das aulas tradicionais, o que chamou muito atenção dos discentes na hora da aprendizagem. Quando antes abordado o assunto de maneira simples, os alunos achavam cansativos e estressantes, utilizando uma metodologia que use brincadeiras e jogos, interfere ao olhar do aluno, tornando-o entusiasmado com o que faz, e dessa forma aprendendo. Que foi o que aconteceu com os aprendizes do primeiro ano. Apesar da sala ser numerosa e difícil, eles tomaram foco e participaram de uma forma surpreendente, mostrando interesse e determinação.

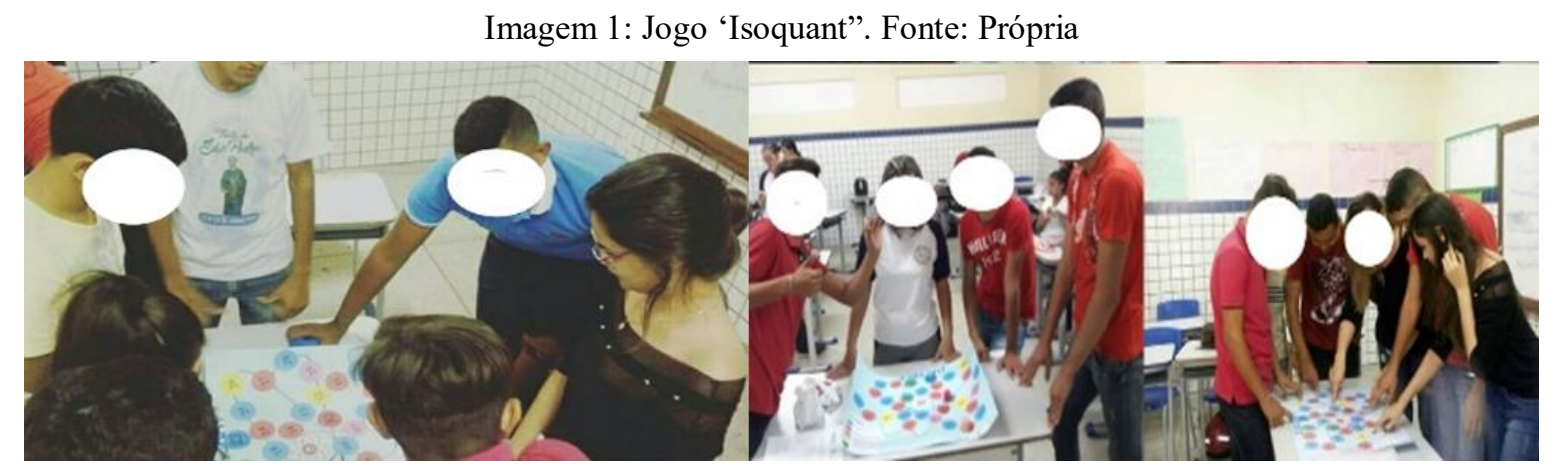

\section{Considerações}

Dessa forma, conclui-se que houve uma melhor aprendizagem dos alunos devido ao estimulo do jogo como uma forma que alia a função educativa ao lúdico. A aplicação do jogo proporcionou experiências ímpar, formando um elo entre a teoria e a prática, valorizando a prática docente nessa formação de futuros professores.

\section{Referências}

$[1,2]$ OLIVEIRA, Lívia Micaelia Soares; SILVA, Oberto Grangeiro da; FERREIRA, Ulysses Vieira da Silva. DESENVOLVENDO JOGOS DIDÁTICOS PARA O ENSINO DE QUÍMICA. Holos, [s.1.], v. 5, p.166-175, 14 mar. 2011.

Instituto Federal de Educacao, Ciencia e Tecnologia do Rio Grande do Norte (IFRN). http://dx.doi.org/10.15628/holos.2010.567. Disponível em: <http://www2.ifrn. edu.br/ojs/index.php/HOLOS/article/view/567>. Acesso em: 13 set. 2017. 